\title{
Syphilis and the Internet
}

M Noll-Hussong (minohu@gmx.net)1

1. Clinic for Psychosomatic Medicine, University of Ulm, Germany

Citation style for this article:

Noll-Hussong M. Syphilis and the Internet. Euro Surveill. 2012;17(33):pii=20249. Available online: http://www.eurosurveillance.org/ViewArticle. aspx?Articleld $=20249$

Article submitted on 14 August 2012 / published on 16 August 2012

\section{To the editor:}

Based on surveillance data generated from national laboratory findings collected by the Robert Koch Institute, Bremer et al. [1] demonstrated that there was an increase in the incidence of syphilis in Germany in 2011. In their article, the authors focused on the persuasive power of traditional microbiologically-confirmed data. However, a recently evolving 'social' surveillance tool could also be considered: Internet search engine analytics.

The power of search engine analytics to detect infectious diseases (e.g. influenza) has been demonstrated [2], and it would make sense that this tool would be useful in the surveillance of other contagious diseases [3], especially sexually transmitted infections (STI). The ongoing stigmatisation of STIs, the perceived anonymity of Internet usage, and last but not least, the habits of the primary risk group, i.e. men who have sex with men (MSM) [4], who utilise the Internet to find sexual partners, makes it seem obvious that many individuals, when recognising new suspect symptoms, will first and foremost use information provided on the Internet, which is easily accessible via search engines. Indeed, and despite the inherent problems with Internet-based digital data retrieval [5], the interest for syphilis over time, in terms of web searches, can be for example investigated with Google Insights for Search (http://www.google.com/insights/search/) by enquiring on the search term 'syphilis', in Germany from 2004 to present, within the category 'Sexually Transmitted Diseases'. This allows graphical visualisation of the level of interest for 'syphilis' relative to that for 'Sexually Transmitted Diseases' over this period in Germany. An increase in the searches for 'syphilis' relative to 'Sexually Transmitted Diseases' can be observed from mid-2010.
Because, for example, various efforts to establish an effective partner notification system for syphilis patients have had differing levels of success, new methods for limiting or preventing the spread of syphilis should be developed, and these new methods should take into consideration the habits and reachability of young males in the 21st century. For example, when a person searches for the selected term, the top search results can be presented in the form of suggestions for counselling or therapy using the search patterns that Google computes for each of its search engine users for marketing purposes. In this scenario, these patterns would not be used for marketing but to promote health.

\section{References}

1. Bremer V, Marcus U, Hamouda O. Syphilis on the rise again in Germany - results from surveillance data for 2011. Euro Surveill. 2012;17(29): pii=20222. Available from: http://www. eurosurveillance.org/ViewArticle.aspx?Articleld=20222

2. Ginsberg J, Mohebbi MH, Patel RS, Brammer L, Smolinski MS, Brilliant $L$ et al. Detecting influenza epidemics using search engine query data. Nature. 2009;457(7232):1012-4.

3. Hulth A, Rydevik G. GET WELL: an automated surveillance system for gaining new epidemiological knowledge. BMC Public Health. 2011;11:252.

4. Van de Laar M, Spiteri G. Increasing trends of gonorrhoea and syphilis and the threat of drug-resistant gonorrhoea in Europe. Euro Surveill. 2012;17(29):pii=20225. Available from: http:/ www.eurosurveillance.org/ViewArticle.aspx?Articleld $=20225$

5. Brownstein JS, Freifeld CC, Madoff LC. Digital disease detection--harnessing the Web for public health surveillance. $\mathrm{N}$ Engl J Med. 2009;360(21):2153-5, 2157. 